For Journal of Asia-Pacific Entomology

\title{
Nitric Oxide Fumigation for Control of Western Flower Thrips and its Safety to Postharvest Quality of Fresh Fruit and Vegetables
}

\author{
Yong-Biao Liu \\ Crop Improvement and Protection Unit \\ USDA-ARS, Salinas, CA 93905 USA \\ Email: yongbiao.liu@ars.usda.gov
}

Tel: (831) 755-2825

USDA is an equal opportunity provider and employer.

Mention of trade names or commercial products in this publication is solely for the purpose of providing specific information and does not imply recommendation or endorsement by the U.S. Department of Agriculture. 


\section{ABSTRACT}

Nitric oxide fumigation under ultralow oxygen conditions was studied for controlling western flower thrips and effects on postharvest quality of fresh fruit and vegetables. Four hour fumigation with $1 \%$ nitric oxide at $2^{\circ} \mathrm{C}$ and $3 \mathrm{~h}$ fumigation with $2 \%$ nitric oxide at $5^{\circ} \mathrm{C}$ achieved complete control of the thrips. The $4 \mathrm{~h}$ treatment was tested on 10 fresh fruit and vegetables including lettuce, broccoli, pepper, squash, tomato, apple, lemon, orange, peach, and pear. When the treatment was terminated by flushing with nitrogen to dilute nitric oxide before exposing the products to ambient air, the treatment had no negative impact on quality of the products. When the treatment was terminated by flushing with air to allow nitric oxide to reacts with oxygen in the air to form nitrogen dioxide, the treatment caused injuries to the majority of the fresh products. Fresh products with thick and robust skins were more tolerant than those with thin and delicate skins to nitric oxide fumigation. The $4 \mathrm{~h}$ fumigation with $1 \%$ nitric oxide of strawberries at $2{ }^{\circ} \mathrm{C}$ had positive impact on strawberry quality with enhanced firmness, brighter and richer color than the controls. The study demonstrated efficacy of nitric oxide fumigation in controlling western flower thrips, safety to fresh commodities, and benefits to postharvest quality of strawberries.

Keywords: Nitric oxide, western flower thrips, phytosanitary, postharvest quality, quarantine treatment, strawberry 


\section{Introduction}

Postharvest pest control is critical to international trade and food security. As methyl bromide production is being phased out globally, its future availability for postharvest pest control is bleak and alternative treatments are urgently needed. However, there is a severe lack of new alternative treatments especially for fresh commodities. Phosphine has now became the dominant methyl bromide alternative for postharvest pest control. However, phosphine is not effective against some pests because of tolerance or pesticide resistance and also has long treatment times (Hole et al. 1976, Schlipalius et al. 2002). In comparison, nitric oxide, a newly discovered fumigant, has the potential to become an effective and safe methyl bromide alternative for postharvest pest control.

Nitric oxide is a natural cell messenger chemical in most biological systems including insects and has been used to treat respiratory and cardiac illnesses (Culotta and Koshland 1992, Roberts et al. 1993, Rossaint et al. 1993, Müller 1997, Davies 2000, Ricciardolo et al. 2004). It is also released as a common pollutant from fossil fuel combustion in power plants and motor vehicles in large quantities and produced commercially as an intermediate in fertilizer production. In agriculture, nitric oxide has been used over 100 years ago for red pigment preservation in preserved meat products (Haldane 1901). More recently, nitric oxide was found to extend shelf-life and enhance postharvest quality of a wide variety of fresh products including strawberries (Wills et al. 2000, Soegiarto et al. 2003, Soegiarto and Wills 2004, Wills et al. 2007, Manjunatha et al. 2012, Saadatian et al. 2012).

In a recent study, nitric oxide fumigation under ultralow oxygen atmosphere was found to be effective against a wide variety of insects at different life stages (Liu 2013). Effective control of western flower thrips (Frankliniella occidentalis) and lettuce aphid (Liriomyza langei), were 
achieved in $3 \mathrm{~h}$ at a high concentration of $2.0 \%$ at $2^{\circ} \mathrm{C}$. All life stages of confused flour beetle (Tribolium confusum) and rice weevil (Sitophilus oryzae) were controlled in $24 \mathrm{~h}$ with $2.0 \% \mathrm{NO}$ at $\geq 10^{\circ} \mathrm{C}$ and $48 \mathrm{~h}$ with $1 \% \mathrm{NO}$ at $25^{\circ} \mathrm{C}$ respectively (Liu 2013). Effective controls of codling moth (Cydia pomonella) and spotted wing drosophila (Drosophila suzukii) were also achieved (Liu 2015, Liu et al. 2016). These results indicate the good potential of nitric oxide fumigation for postharvest pest control. Treatment times of nitric oxide fumigation for controlling western flower thrips and lettuce aphid are much shorter than those of low temperature phosphine fumigation. Low temperature phosphine fumigation takes at least $18 \mathrm{~h}$ and $72 \mathrm{~h}$ to control western flower thrips and lettuce aphid respectively at $2^{\circ} \mathrm{C}$ (Liu 2008, 2012). Therefore, although data are still limited, at least for some insects, nitric oxide fumigation is much more effective than phosphine fumigation. In addition, nitric oxide fumigation does not leave toxic residues on fumigated fresh products (Liu and Yang 2016).

Nitric oxide reacts with oxygen spontaneously to form nitrogen dioxide (Ashmore et al. 1962). Therefore, nitric oxide fumigation needs to be conducted under ultralow oxygen conditions to minimize oxidation of nitric oxide. Feasibility of practical use of nitric oxide fumigation for postharvest pest control also depends on the safety of the treatment to product quality. Even though nitric oxide fumigation has been demonstrated to be beneficial to shelf-life of many fresh products, the concentrations of nitric oxide used in the treatment for postharvest quality enhancement are much lower as compared with the concentrations used for postharvest pest control (Wills et al. 2000, Soegiarto et al. 2003, Soegiarto and Wills 2004, Wills et al. 2007, Manjunatha et al. 2012, Saadatian et al. 2012, Liu 2013). It is therefore important to know whether nitric oxide fumigations at high concentrations can be conducted safely on fresh products and whether the fumigation treatments for pest control can still have beneficial effects on postharvest quality. Strawberries are delicate and have a relatively short postharvest shelf-life. 
It would be an attractive option if nitric oxide fumigation can be used to control quarantine pests as well as to extend shelf-life of strawberries.

Western flower thrips, Frankliniella occidentalis (Pergande) (Thysanoptera: Thripidae), is a common pest on a variety of crops in the U.S. However, it is a quarantine pest in Taiwan and therefore affects exports of U.S. fresh fruit and vegetables. An alternative treatment is needed to control the pest on fresh commodities. In this study, nitric oxide fumigation for control of western flower thrips was further refined and was tested on fresh fruit and vegetables including strawberries to determine whether nitric oxide fumigation can effectively control western flower thrips and is safe to postharvest quality of fresh fruit and vegetables.

\section{Materials and Methods}

\section{Chemicals and Insect}

Nitric oxide (>99.5\% purity) in a compressed cylinder was obtained from a commercial source. It was then released and stored in a foil bag ( 7.5 mils MylarFoil, $20 \mathrm{~cm}$ by $40 \mathrm{~cm}$, Impak Corp., Los Angeles, CA) to be used in fumigations tests. Commercial grade nitrogen gas in compressed cylinders from a commercial source (Praxair, Salinas, CA) was used. Western flower thrips, Frankliniella occidentalis (Thysanoptera: Thripidae), from naturally infested lettuce plants in a greenhouse were reared on lettuce plants in a greenhouse at $18-30^{\circ} \mathrm{C}$ under natural lighting (Liu 2008). Both larvae and adults were collected in small plastic vials $(3 \mathrm{~cm}$ in diameter by 7 $\mathrm{cm}$ in height) each containing a piece of lettuce leaf using a vacuum powered aspirator (ca. 20/vial). The vials with thrips were sealed with screened lids and kept at $2^{\circ} \mathrm{C}$ overnight in a temperature chamber before being used in fumigation tests.

Nitric oxide fumigation of western flower thrips 
Thrips in plastic vials were fumigated in $1.9 \mathrm{~L}$ glass jars for $4 \mathrm{~h}$ at $2^{\circ} \mathrm{C}$ with nitric oxide under ultralow oxygen conditions using procedures of Liu (2013). Sealed fumigation jars were first flushed with nitrogen gas to establishing ultralow oxygen levels of $\leq 30 \mathrm{ppm}$. Oxygen levels in the jars were monitored using an oxygen analyzer (Series 800, Illinois Instruments, Inc., Johnsburg, IL, USA). Nitric oxide gas was then injected into each treatment jar using an airtight syringe in a fume hood to establish pre-calculated nitric oxide concentrations of $0.3 \%, 0.5 \%$, $0.7 \%$, and $1.0 \%$ based on volume. The syringe and connecting tubing were flushed with nitrogen prior to injection of nitric oxide to avoid oxidation of nitric oxide. Untreated thrips in the normal air and under ULO conditions were used as controls. After nitric oxide injection, the jars were kept at $2^{\circ} \mathrm{C}$ in a temperature chamber for the duration of the $4 \mathrm{~h}$ to complete the treatment. Fumigation treatments were terminated by venting the jars under a fume hood. Thrips were kept overnight in an environmental chamber at $22^{\circ} \mathrm{C}, 90-95 \% \mathrm{RH}$, and a 14:10 (L:D) photoperiod before being scored for mortality. Thrips that were motionless, didn't respond to probes with a soft brush, or capable of moving appendages but unable to move were classified as dead. Each treatment was replicated four times. A total of 2433 thrips were used.

\section{Nitric oxide fumigation of fresh fruit and vegetables}

A total of 10 fresh fruit and vegetables were subjected to nitric oxide fumigation treatments with $2.0 \%$ nitric oxide under $\leq 50 \mathrm{ppm} \mathrm{O}_{2}$ for $3 \mathrm{~h}$ at $5^{\circ} \mathrm{C}$ to determine effects on postharvest quality of fresh products. All products were from supermarkets and they were apple, broccoli, lemon, romaine lettuce, orange, peach, pear, pepper, squash, and tomato. They were fumigated together in 21.8 liter chambers modified from pressure cookers. Two fumigation treatments were tested and both were identical except that one treatment $\left(\mathrm{NO}-\mathrm{N}_{2}\right)$ was terminated by flushing the chamber with nitrogen to dilute NO before opening the chamber to ambient air 
and the other treatment (NO-Air) was terminated by flush the chamber with air to allow nitric oxide to react with oxygen in the air to produce nitrogen dioxide. As nitric oxide reacts with oxygen spontaneously and exothermally to produce nitrogen dioxide, the opening of the fumigation chambers at the end of fumigation treatments may result in momentary exposure of fumigated products to the reaction between nitric oxide and oxygen as well as its product nitrogen dioxide. The treatment terminated by flushing with nitrogen was to demonstrate whether flushing with nitrogen at the end of fumigation could prevent any possible negative impact of nitric oxide fumigation on product quality. Controls were stored at $5^{\circ} \mathrm{C}$ during the fumigations.

In each test, most products had 2-3 individuals per treatment. Apple and pear each had 5 in each treatment. Products were placed in perforated plastic bags in groups and then sealed in the fumigation chambers. Western flower thrips larvae and adults contained in small plastic vials were also included in both treatments to be fumigated. Untreated controls were stored at $5^{\circ} \mathrm{C}$ during fumigation. The chambers were flushed with nitrogen through two outlets to establish an ultralow oxygen (ULO) condition of $\leq 50 \mathrm{ppm}$ and were then injected with predetermined volumes of nitric oxide gas to establish a calculated concentration of $2.0 \%$ under a fume hood in room temperature. The chambers were then kept in a refrigerator at $5^{\circ} \mathrm{C}$ for $3 \mathrm{~h}$ to complete the fumigation. At the end of the fumigation, the $\mathrm{NO}-\mathrm{N}_{2}$ treatment chamber was flushed with nitrogen at $5 \mathrm{l} / \mathrm{min}$ for $20 \mathrm{~min}$ and the NO-Air treatment chamber was flushed with air at $5 \mathrm{l} / \mathrm{min}$ for $20 \mathrm{~min}$ in a fume hood before they were open to the ambient air. After fumigation, western flower thrips were stored overnight in an environmental chamber before being scored for mortality as described above.

All products from both treatments and the control were placed in plastic boxes and stored at $2^{\circ} \mathrm{C}$ for 14 days before being scored for postharvest quality. The test was replicated three times. The 
products' marketability was visually scored using the 1 (extremely poor) to 9

(excellent) scale for lettuce (Kader et al. 1973) with 3, 5, and 7 representing poor, fair with

major defects, and good with minor defects (Liu 2012). Injuries from fumigation in the form of dead tissues were also recorded.

Nitric oxide fumigation of strawberries

Harvested fresh strawberries together with western flower thrips were fumigated with $1 \% \mathrm{NO}$ for $4 \mathrm{~h}$ at $2^{\circ} \mathrm{C}$ to determine efficacy and the effects of the treatment on strawberry quality. Commercial fresh strawberries in retail clamshell plastic boxes were obtained one day after harvest from Driscoll's (Watsonville, CA), chilled to $2^{\circ} \mathrm{C}$ in a temperature chamber, and immediately used in fumigation tests. The fumigation test had only one treatment and a control and all fumigations of strawberries were conducted in the $21.8 \mathrm{~L}$ chambers. The fumigation treatment was terminated by flushing with nitrogen gas.. The fumigation chamber was first flushed with nitrogen gas to establish ultralow oxygen levels of $<50 \mathrm{ppm}$. Nitric oxide gas from the foil bag was then injected into the chamber to establish a projected concentration of $1.0 \%$. B o th the fumigation and the control chambers were then kept in a refrigerator at $2^{\circ} \mathrm{C}$ for 4 hours. At the end of fumigation, the treatment chamber was flushed with nitrogen gas at 5 1/min for $20 \mathrm{~min}$ and then opened to ambient air. Western flower thrips in vials were taken out from the chamber and stored overnight in an environmental chamber at $15^{\circ} \mathrm{C}$ before being scored for mortality as described above. The strawberries in clamshell boxes from both the treatment and the control chambers were then packed in a cardboard tray and stored in a walkin cooler at $2^{\circ} \mathrm{C}$ for 7 days before post-treatment quality evaluation.

For each test, 40 strawberries from the fumigation treatment and 40 strawberries from the control were randomly taken to be evaluated for color, firmness, and damages to calyx and berry 
using previously described procedures (Liu 2008). A spectrophotometer (ColorTec-PSM, Accuracy Microsensors, Inc., Pittsford, NJ) was used to measure colors on two opposite sides of each berry, and the average values of $L^{*}, C$, and $H^{\circ}$ representing luminosity, chrome, and hue angle were used for statistical analyses. Firmness of each berry were measured twice on the two opposite sides with a handheld penetrometer fitted with a 3-mm round tip and measured as forces in grams to penetrate the skin. The average value of firmness for each berry was used in statistical analyses. Berry damages were scored in a range of 1 to 4 as described by Simpson et al. (2003) and Liu (2008). Berry damages included bruising, decay, and surface disintegration. The damage scores of 1, 2, 3, and 4 represented no damage, slight ( $<20 \%$ surface area affected), moderate (20-60\% surface area affected), and severe (>60\% surface affected), respectively.

\section{Data analyses}

Mortality data of western flower thrips in the small scale tests were transformed by arcsinevx prior to statistical analyses. One-way analysis of variance (ANOVA) was used to compare insect mortalities among different nitric oxide concentrations and to compare product quality scores among different treatments. Tukey HSD multiple range tests were used to compare means at $\mathrm{p}=0.05$ using Fit-model of JMP statistical discovery software (SAS Institute 2012).

\section{Results}

Nitric oxide fumigation treatments at all concentrations were effective against thrips with a mortality rate of $82.7 \%$ at the lowest nitric oxide concentration of $0.3 \%$ and $100 \%$ mortality for $1.0 \%$ nitric oxide fumigation and there were significant differences in mortality among different treatments $(\mathrm{F}=538.9831, \mathrm{df}=5,66, \mathrm{P}<0.0001)$ (Table 1). Mortalities in controls (normal air 
and ultralow oxygen atmosphere) were minimal, indicating that 4 hours of ultralow oxygen condition did not have significant impact on thrips survival. In both $3 \mathrm{~h}$ fumigations with $2 \%$ $\mathrm{NO}$ of fruit and vegetables and $4 \mathrm{~h}$ fumigations with $1 \% \mathrm{NO}$ of strawberries, $100 \%$ mortality of western flower thrips was achieved.

In the $3 \mathrm{~h}$ fumigation of fruits and vegetables, there were no significant difference between NO-N 2 and control in postharvest quality for all products (Table 2). However, there were considerable variations among different fresh products in sensitivity to NO-Air treatment. NO-Air treatment had significantly lower visual quality scores as compared with NO-N 2 treatment or control for apple, broccoli, lettuce, peach, pear, pepper, and squash. There were no significant differences among the three treatments including control for lemon, orange, and tomato (Table 2). The significant reductions in visual quality score were due to injuries by nitrogen dioxide and had symptoms of discoloration or stains. As showing in figure 1, lettuce from NO-Air treatment showed patches of dead leaf tissue. The same treatment caused gray or brownish stains on broccoli, dark spots on apples and pears, and discolorations of orange and peach (Fig. 1).

The 4 hour nitric oxide fumigation at $1.0 \%$ concentration had positive effects on postharvest quality of strawberries (Table 3). Fumigated strawberries were significantly firmer and also had significantly higher values of $\mathrm{L}^{*}$ (luminosity) and $\mathrm{C}$ (Chroma) values of color measurements than the controls. There were no significant differences in the level of surface damage and $\mathrm{H}^{\circ}$ angle between the treatment and the control. Higher firmness indicates slower ripening and disintegration. Higher values of $\mathrm{L}^{*}$ and $\mathrm{C}$ represent bright and richer color and therefore also represent higher berry quality. The non-significant difference in $\mathrm{H}^{\circ}$ indicates that there was no significant color change. 


\section{Discussion}

Nitric oxide fumigation was effective in controlling western flower thrips in 4 hours or less at a low storage temperature of $2-5^{\circ} \mathrm{C}$. These results confirmed the high efficacy of nitric oxide fumigation against western flower thrips in the earlier study (Liu 2013). Even though it takes time to establish ULO environment to initiate nitric oxide fumigation, the fumigation duration is relatively short. In comparison, phosphine fumigation at low temperature for control of western flower thrips requires at least 18 hours (Liu 2008). Therefore, nitric oxide fumigation has high efficacy in controlling western flower thrips for commercial applications.

When terminated properly by flushing with nitrogen to dilute nitric oxide at the end of fumigation, nitric oxide fumigation was safe to all fresh fruits and vegetables tested in small scale tests. Nitric oxide fumigation also had positive effects in extending shelf-life of strawberries. This is consistent with the earlier finding that fumigation with 5-10 $\mu 11^{-1}$ nitric oxide can extend shelf-life of strawberries by over 50\% (Wills et al. 2000). These results suggest that nitric oxide fumigation not only was safe to fresh products but may also be used both to control pests and to extend shelf-life of some delicate fresh fruits such as strawberries. Because strawberries are delicate with short postharvest storage life, the market window for strawberries is narrow, limiting their distribution and market reaches. Nitric oxide fumigation may have a potential to change this. It not only solves postharvest pest problems but may also expand markets for strawberries.

The differences in sensitivity to NO-Air among different fresh products were likely due to physical properties of different products. Apple, lemon, orange, and tomato have more steady skins as compared with others such as lettuce, broccoli, peach, pear, and squash which have thin and more delicate skins. Fruits with robust steady skins seem to be more tolerant to exposures to 
produced $\mathrm{NO}_{2}$ at the end of nitric oxide fumigation. It is possible that some fruits with thicker skins/peels may be able to tolerate nitric oxide fumigations without flushing with nitrogen to end the treatments. Others such lettuce, broccoli, and squash were more sensitive to $\mathrm{NO}_{2}$. Nitric oxide fumigations for these sensitive commodities need to be terminated by flushing with nitrogen to reduce nitric oxide concentrations to a very low level to ensure product safety. For those sensitive products packed in plastic sleeves or cartons, it may take considerable time to flush out nitric oxide at the end of fumigation. Therefore, large scale fumigation trial with commercially packed product is needed to investigate the safety of nitric oxide fumigation.

Although methyl bromide is still exempted for pre-shipping fumigations for quarantine treatments, it may not be available in the future. In addition, methyl bromide fumigation is expensive and commodities in cold storage need to be warmed up to above $40{ }^{\circ} \mathrm{F}$ for treatment and thereby impact negatively on commodity quality. Nitric oxide fumigation can be conducted at cold storage temperature and therefore $\mathrm{th}$ e $\mathrm{e}$ is $\mathrm{no}$ n e gative im pact on $\mathrm{qu}$ a $\mathrm{l}$ i t y of fresh products in the cold storage. The treatment duration for thrips control was also short enough to be comparable with methyl bromide fumigation.

Nitric oxide fumigation for control of the western flower thrip was much shorter than low temperature phosphine fumigation of at least 18 hours as reported by Liu (2008). Even with additional time for establishing ultralow oxygen conditions prior to injection of nitric oxide, the total time for nitric oxide fumigation would be substantially shorter than phosphine fumigation. It is likely to be the case for many other insects tested (Liu 2013).

Short treatment time with nitric oxide fumigation have the potential to reduce fumigation cost substantially. Fumigation chambers with suitable refrigeration systems may be needed in many cases to conduct phosphine fumigation at low temperature for long treatment time and low 
temperature fumigation chambers are expensive. In contrary, such low temperature fumigation chambers may not be needed for nitric oxide fumigations. Certain levels of insulation of fumigation chambers may be enough to slow down temperature rises during the short fumigation period to prevent negative impact on product quality. In an early study, the temperature of chilled lettuce in a pallet scale phosphine fumigation treatment under bubble insulation increased slowly over time by $3^{\circ} \mathrm{C}$ in 18 hours (Liu 2010). It is likely that the much shorter fumigation with nitric oxide would have only minimal product temperature changes during fumigation.

This study demonstrated high efficacy of nitric oxide fumigation against western flower thrip and its safety to strawberries and other ten fresh products when fumigation treatments were terminated properly by flushing with nitrogen gas to minimize exposure of fresh products to nitrogen dioxide. The study showed that nitric oxide fumigation has good potential to become an effective and safe alternative for postharvest quarantine treatment. However, large scale trials are needed to verify its efficacy and safety to product quality to develop practical quarantine treatments. 


\section{Acknowledgments}

I thank T. Masuda and J. Wasson for technical support. I also thank Driscoll's for supplying harvested strawberries. This study was supported in part by funding from U. S. Department of Agriculture, Foreign Agricultural Services. 


\section{References}

Ashmore, P.G., Burnett, M.G., Tyler, B.J., 1962. Reaction of nitric oxide and oxygen. Trans. Faraday Soc. 58: 685-691.

Culotta, E., Koshland, D.E. Jr., 1992. NO news is good news. Sci. 258: 1862-1865.

Davies, S., 2000. Nitric oxide signaling in insects. Insect Biochem. Mol. Biol. 30: 1123-1138.

Haldane, J., 1901. The red colour of salted meat. J. Hyg. 1: 115-122.

Hole, B.D., Bell, C.H., Mills, K.A., Goodship, G., 1976. The toxicity of phosphine to all developmental stages of thirteen species of stored product beetles. J. Stored Prod. Res. 12: $235-244$.

Kader, A.A., Lipton, W.J., Morris, L.L., 1973. Systems for scoring quality of harvested lettuce. HortScience 8, 408-409.

Liu, Y.-B., 2008. Low temperature phosphine fumigation for postharvest control of western flower thrips (Thysanoptera: Thripidae) on lettuce, broccoli, asparagus, and strawberry. J. Econ. Entomol. 101: 1786-1791.

Liu, Y.-B., 2010. Low-temperature phosphine fumigation of chilled lettuce under insulated cover for postharvest control of western flower thrips, Frankliniella occidentalis (Pergande) (Thysanoptera: Thripidae). J. Asia-Pacific Entomol. 14: 323-325.

Liu, Y.-B., 2012. Oxygenated phosphine fumigation for control of Nasonovia ribisnigri (Homoptera: Aphididae) on harvested lettuce. J. Econ. Entomol. 105: 810-816.

Liu, Y.-B., 2013. Nitric oxide as a potent fumigant for postharvest pest control. J. Econ. Entomol. 106: 2267-2274.

Liu, Y.-B., 2015. Nitric oxide as a new fumigant for postharvest pest control on fresh commodities. Acta Horticulturae 1105: 321-317. 
codling moth in apples. Insects (in press).

Liu, Y.-B., Yang, X. 2016, Prospect of nitric oxide as a new fumigant for postharvest pest control. Proc. 10th Intl. Conf. Controlled Atmosphere and Fumigation in Stored Products, Nov. 7-11, 2016, New Delhi, India (in press).

Manjunatha, G., Lokesh, V., Bhagyalashmi, N., 2012. Nitric oxide-induced enhancement of banana fruit attributes and keeping quality. Acta Hort. 934: 799-806.

Müller, U., 1997. The nitric oxide system in insects. Prog. Neurobiol. 51: 363-381.

Ricciardolo, F.L.M., Sterk, P.J., Gaston, B., Folkerts, G., 2004. Nitric oxide in health and disease of the respiratory system. Physiol. Rev. 84: 731-765.

Roberts, J.D. Jr, Lang, P., Bigatello, L.M., Vlahakes, G.J., Zapol, W.M., 1993. Inhaled nitric oxide in congenital heart disease. Circulation 87: 447-453.

Rossaint, R., Falke, K.J., Lopez, F., Slama, K., Pison, U., Zapol, W.M., 1993. Inhaled nitric oxide for the adult respiratory distress syndrome. N. Engl. J. Med. 1993: 328:399-405. Saadatian, M., Ahmadiyan, S., Akbari, M., Balouchi, Z., 2012. Effects of pretreatment with nitric oxide on kiwifruit storage at low temperature. Adv. Environ. Biol. 6: 1902-1908.

SAS Institute, 2012. JMP Statistic Discovery Software v10, Cary, NC.

Schlipalius, D.I., Cheng, Q., Reilly, P.E.B., Collins, P.J., Ebert, P.R., 2002. Genetic linkage analysis of the lesser grain borer Rhyzopertha dominica identifies two loci that confer highlevel resistance to the fumigant phosphine. Genetics 161: 773-782.

Simpson, T., Bikoba, V., Mitcham, E.J., 2003. Effects of acetaldehyde on fruit quality and target pest mortality for harvested strawberries. Postharvest Biol. Technol. 28: 405-416.

Soegiarto, L., Wills, R.B.H., Seberry, J.A., Leshem, Y.Y., 2003. Nitric oxide degradation in oxygen atmospheres and rate of uptake by horticultural produce. Posth. Biol. Technol. 28: $327-332$. 
Soegiarto, L., Wills, R.B.H., 2004. Short term fumigation with nitric oxide gas in air to extend the postharvest life of broccoli, green bean, and bok choy. HortTechnol. 14: 538-540.

Wills, R.B.H., Ku, V.V.V., Leshem, Y.Y., 2000. Fumigation with nitric oxide to extend the postharvest life of strawberries. Posth. Biol. Technol. 18: 75-79.

Wills, R.B.H., Soegiarto, L., Bowyer, M.C., 2007. Use of a solid mixture containing diethylenetriamine/nitric oxide (DETANO) to liberate nitric oxide gas in the presence of horticultural produce to extend postharvest life. Nitric Oxide 17: 44-49. 
Table 1. Mortality of western flower thrips in response to nitric oxide fumigation treatments at low temperatures

\begin{tabular}{|c|c|c|c|c|}
\hline NO (\%) & Time (h) & Temp $\left({ }^{\circ} \mathrm{C}\right)$ & $\mathrm{N}$ & 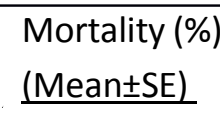 \\
\hline \multicolumn{5}{|c|}{ Fumigation in $1.9 \mathrm{~L}$ jars without product } \\
\hline 0.3 & 4 & 2 & 231 & $82.7 \pm 3.6 b$ \\
\hline 0.5 & 4 & 2 & 246 & $95.8 \pm 2.4 a$ \\
\hline 0.7 & 4 & 2 & 245 & $99.5 \pm 0.5 a$ \\
\hline 1.0 & 4 & 2 & 247 & $100 a$ \\
\hline & (ULO) & 2 & 232 & $4.4 \pm 1.5 \mathrm{c}$ \\
\hline & & 2 & 242 & $6.6 \pm 1.8 \mathrm{c}$ \\
\hline \multicolumn{5}{|c|}{ Fumigation in $21.8 \mathrm{~L}$ chamber with strawberries } \\
\hline \multirow[t]{2}{*}{1.0} & 4 & 2 & 380 & 100 \\
\hline & & 2 & 180 & 0 \\
\hline \multicolumn{5}{|c|}{ Fumigation in $21.8 \mathrm{~L}$ chamber with fruits and vegetables } \\
\hline 2.0 & 3 & 5 & 320 & 100 \\
\hline \multicolumn{2}{|c|}{ Control } & 5 & 110 & 0 \\
\hline
\end{tabular}

Mortalities for different nitric oxide concentrations in fumigations in $1.9 \mathrm{~L}$ jars were transformed by arcsinevx prior to analysis of variance. Mortalities from different treatments were compared using Tukey HSD multiple range test ( $P \leq 0.05)$ (SAS Institute 2012). 
Table 2. Effects of nitric oxide fumigation treatments on postharvest quality of fresh fruit and vegetables after $14 \mathrm{~d}$ post-treatment storage at $2 \mathrm{C}$

\begin{tabular}{|c|c|c|c|c|c|}
\hline Product & Treatment & $\mathrm{N}$ & Quality score & \multicolumn{2}{|c|}{ ANOVA } \\
\hline \multirow[t]{3}{*}{ Lettuce } & Control & 7 & $6.4 \pm 0.9 a$ & $d f=2,18$ & $F=15.754$ \\
\hline & $\mathrm{NO}-\mathrm{N}_{2}$ & 7 & $4.9 \pm 0.6 a$ & & $P=0.0001$ \\
\hline & NO-Air & 7 & $1.4 \pm 0.2 b$ & & \\
\hline \multirow[t]{3}{*}{ Broccoli } & Control & 7 & $8.0 \pm 0.3 a$ & $d f=2,17$ & $F=9.193$ \\
\hline & $\mathrm{NO}-\mathrm{N}_{2}$ & 7 & $7.9 \pm 0.5 a$ & & $P=0.0020$ \\
\hline & NO-Air & 6 & $5.2 \pm 0.7 b$ & & \\
\hline \multirow[t]{3}{*}{ Pepper } & Control & 15 & $8.1 \pm 0.2 a$ & $d f=2,42$ & $F=9.026$ \\
\hline & $\mathrm{NO}-\mathrm{N}_{2}$ & 15 & $7.3 \pm 0.3 a$ & & $P=0.0005$ \\
\hline & NO-Air & 15 & $6.0 \pm 0.5 b$ & & \\
\hline \multirow[t]{3}{*}{ Squash } & Control & 7 & $7.1 \pm 0.3 a$ & $d f=2,18$ & $F=9.546$ \\
\hline & $\mathrm{NO}-\mathrm{N}_{2}$ & 7 & $6.6 \pm 0.2 a$ & & $P=0.002$ \\
\hline & NO-Air & 7 & $4.1 \pm 0.8 b$ & & \\
\hline \multirow[t]{3}{*}{ Tomato } & Control & 9 & $8.3 \pm 0.3 a$ & $d f=2,24$ & $F=2.886$ \\
\hline & $\mathrm{NO}-\mathrm{N}_{2}$ & 9 & $7.6 \pm 0.4 a$ & & $P=0.075$ \\
\hline & NO-Air & 9 & $6.9 \pm 0.5 a$ & & \\
\hline \multirow[t]{3}{*}{ Apple } & Control & 15 & $7.9 \pm 0.2 a$ & $d f=2,42$ & $F=11.667$ \\
\hline & $\mathrm{NO}-\mathrm{N}_{2}$ & 15 & $8.1 \pm 0.2 a$ & & $P<0.0001$ \\
\hline & NO-Air & 15 & $6.3 \pm 0.3 b$ & & \\
\hline \multirow[t]{3}{*}{ Lemon } & Control & 7 & $8.4 \pm 0.3 a$ & $d f=2,18$ & $F=0.214$ \\
\hline & $\mathrm{NO}-\mathrm{N}_{2}$ & 7 & $8.3 \pm 0.3 a$ & & $P=0.809$ \\
\hline & NO-Air & 7 & $8.1 \pm 0.3 a$ & & \\
\hline \multirow[t]{3}{*}{ Orange } & Control & 7 & $8.4 \pm 0.2 a$ & $d f=2,18$ & $F=0.079$ \\
\hline & $\mathrm{NO}-\mathrm{N}_{2}$ & 7 & $8.4 \pm 0.2 a$ & & $P=0.924$ \\
\hline & NO-Air & 7 & $8.3 \pm 0.4 a$ & & \\
\hline \multirow[t]{3}{*}{ Peach } & Control & 7 & $8.4 \pm 0.2 a$ & $d f=2,18$ & $F=6.584$ \\
\hline & $\mathrm{NO}-\mathrm{N}_{2}$ & 7 & $7.4 \pm 0.3 a b$ & & $P=0.007$ \\
\hline & NO-Air & 7 & $5.1 \pm 1.1 b$ & & \\
\hline \multirow[t]{3}{*}{ Pear } & Control & 9 & $8.1 \pm 0.3 a$ & $d f=2,24$ & $F=5.375$ \\
\hline & $\mathrm{NO}-\mathrm{N}_{2}$ & 9 & $8.3 \pm 0.2 \mathrm{a}$ & & $P=0.012$ \\
\hline & NO-Air & 9 & $6.8 \pm 0.5 b$ & & \\
\hline
\end{tabular}


Table 3. Effects of nitric oxide fumigation on quality traits of strawberries

\begin{tabular}{lllllll}
\hline Treatment & $\mathrm{N}$ & Berry damage & Firmness $(\mathrm{g})$ & $L^{*}$ & $\mathrm{C}$ & $H^{\circ}$ \\
\hline $\mathrm{NO}-\mathrm{N}_{2}$ & 120 & $2.18 \pm 0.06$ & $99 \pm 3$ & $28.8 \pm 0.3$ & $33.8 \pm 0.5$ & $43.0 \pm 0.3$ \\
Control & 120 & $2.14 \pm 0.07$ & $91 \pm 2$ & $27.8 \pm 0.2$ & $32.3 \pm 0.5$ & $42.2 \pm 0.5$ \\
& & & & & & \\
ANOVA & $\mathrm{F}$ & 0.1346 & 4.7138 & 7.1373 & 4.9716 & 2.1738 \\
$(\mathrm{df}=1,238)$ & $\mathrm{P}$ & 0.7141 & 0.0309 & 0.0081 & 0.0267 & 0.1417 \\
& & & & & & \\
\hline
\end{tabular}




\section{Figure caption:}

Figure 1. Examples of typical effects of nitric oxide fumigations on visual appearance of fresh fruit and vegetables after 14 day cold storage. $\mathrm{NO}-\mathrm{N}_{2}$ : Nitric oxide fumigation that was terminated by flushing with nitrogen to dilute nitric oxide in the fumigation chamber; NO-Air: Nitric oxide fumigation that was terminated by flushing the fumigation chamber with air to allow chemical reaction between nitric oxide and oxygen to produce nitrogen dioxide. 


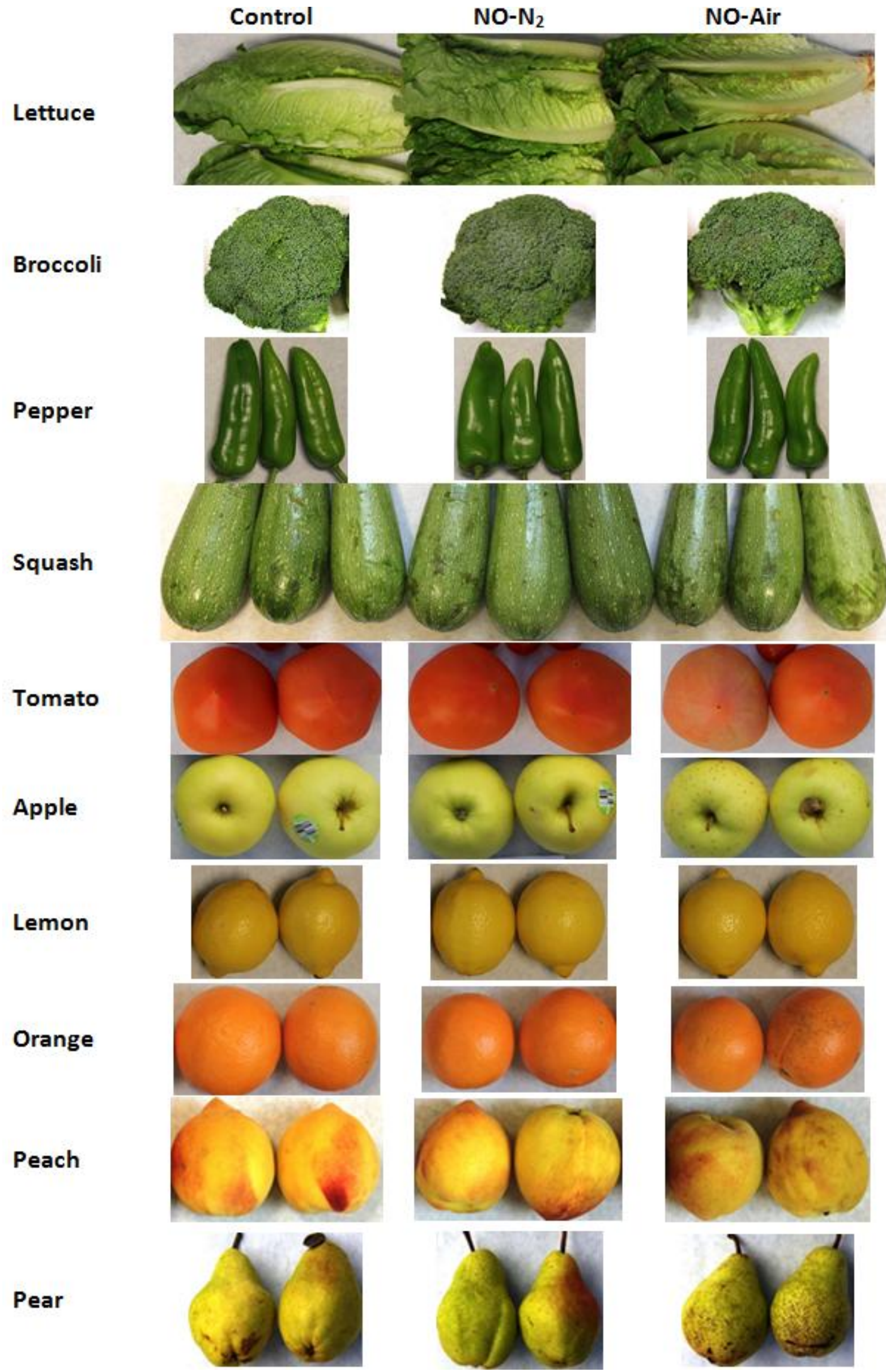

